\title{
What do You Need to Get Male Partners of Pregnant Women Tested for HIV in Resource Limited Settings? The Baby Shower Cluster Randomized Trial
}

\author{
Echezona E. Ezeanolue ${ }^{1,2,7} \cdot$ Michael C. Obiefune ${ }^{3} \cdot$ Wei Yang $^{4} \cdot$ Chinenye O. Ezeanolue $^{2} \cdot$ \\ Jennifer Pharr ${ }^{1,2,7}$ - Alice Osuji ${ }^{3}$. Amaka G. Ogidi ${ }^{3}$ - Aaron T. Hunt ${ }^{1,2}$. \\ Dina Patel ${ }^{1,2} \cdot$ Gbenga Ogedegbe $^{5} \cdot$ John E. Ehiri $^{6}$
}

Published online: 8 December 2016

(C) The Author(s) 2016. This article is published with open access at Springerlink.com

\begin{abstract}
Male partner involvement has the potential to increase uptake of interventions to prevent mother-to-child transmission of HIV (PMTCT). Finding cultural appropriate strategies to promote male partner involvement in PMTCT programs remains an abiding public health challenge. We assessed whether a congregation-based intervention, the Healthy Beginning Initiative (HBI), would lead to increased uptake of HIV testing among male partners of pregnant women during pregnancy. A cluster-randomized controlled trial of forty churches in Southeastern Nigeria randomly assigned to either the HBI (intervention group; IG) or stan-
\end{abstract}

Echezona E. Ezeanolue

echezona.ezeanolue@unlv.edu

Michael C. Obiefune

mobiefune.ihv@gmail.com

Wei Yang

weiyang@unr.edu

Chinenye O. Ezeanolue

anolue76@yahoo.com

Jennifer Pharr

Jennifer.pharr@unlv.edu

Alice Osuji

aaghams.petrgs@gmail.com

Amaka G. Ogidi

aogidi.petrgs@gmail.com

Aaron T. Hunt

aaron.hunt@unlv.edu

Dina Patel

dina.patel@unlv.edu

Gbenga Ogedegbe

Olugbenga.Ogedegbe@nyumc.org

John E. Ehiri

Jehiri@email.arizona.edu dard of care referral to a health facility (control group; CG) was conducted. Participants in the IG received education and were offered onsite HIV testing. Overall, 2498 male partners enrolled and participated, a participation rate of $88.9 \%$. Results showed that male partners in the IG were 12 times more likely to have had an HIV test compared to male partners of pregnant women in the $\mathrm{CG}(\mathrm{CG}=37.71 \%$ vs. $\mathrm{IG}=84.00 \%$; adjusted odds ratio $=11.9 ; \mathrm{p}<.01)$. Culturally appropriate and community-based interventions can be effective in increasing HIV testing and counseling among male partners of pregnant women.
1 Global Health and Implementation Research Initiatives, School of Community Health Sciences, University of Nevada, Las Vegas, 4505 S. Maryland Parkway, Las Vegas, NV, USA

2 HealthySunrise Foundation, 8752 Castle Ridge Avenue, Las Vegas, NV 89129, USA

3 Prevention, Education, Treatment, Training and ResearchGlobal Solutions-PeTR-GS, Plot 25 Liberty Estate, Independence Layout Enugu, Enugu 400001, Enugu State, Nigeria

4 School of Community Health Sciences, Lombardi Recreation Center, University of Nevada, Reno, MS-274, RM212, Reno, NV 89557, USA

5 Center for Healthful Behavior Change, New York University Langone Medical Center, 550 1st Ave, New York, NY, USA

6 Department of Health Promotion Sciences, Mel and Enid Zuckerman College of Public Health, University of Arizona, 1295 N. Martin Ave., Tucson, AZ 85724, USA

7 School of Community Health Sciences, University of Nevada, Las Vegas, 4505 S. Maryland Parkway, Box 454009, Las Vegas, NV 89154-4009, USA 
Keywords Male involvement - HIV testing - Prevention of mother-to-child transmission of HIV · Nigeria .

Community-based research

\section{Introduction}

Research studies have shown that male involvement has a tremendous impact on women's sexual and reproductive health. Male partner involvement has been shown to increase uptake of interventions designed for prevention of mother-to-child HIV transmission (PMTCT) and is associated with decreased infant HIV infection and increased HIV free survival among infants [1-4]. Male partner involvement is necessary to successfully implement the four-pronged comprehensive approach to HIV prevention advocated by the United Nations, which includes primary HIV prevention, supportive counseling for planned pregnancy for women living with HIV, access to antiretroviral therapy for the purpose of preventing mother-to-child transmission (MTCT) of HIV, and ongoing HIV care and support for HIV infected mothers and their infants, partners and families [5]. Couple HIV testing and counseling (HTC) remains an important entry point for male partner engagement in most forms of HIV prevention and care. Despite the promising findings of reduced MTCT with male partner involvement in antenatal care and the desire by women for their male partners' participation, men's involvement in antenatal care and uptake of HTC remains low in sub-Saharan Africa (SSA) [4, 6-9].

Rates of male partners attending at least one antenatal care visit have ranged from 1.8 to $32 \%$ in SSA and barriers to male partner participation in antenatal care and HIV testing have been identified at the individual, community, and health system levels $[1,4,6,7,10-12]$. Lack of awareness about HIV, a perception of low personal risk, mistrust between married couples, and fear of knowing one's status are all identified barriers to men's uptake of HIV testing and engagement in PMTCT [2, 6, 13-15]. Some of the community barriers in SSA are socio-cultural in nature and include gender norms that disapprove of male partners engaging in antenatal activities. This deep seated perception that antenatal activities are a woman's responsibility has limited the role of male partners to only providing financial support during pregnancy [8, 12-14, 16-18]. Health system barriers include poor attitudes of service providers and the timing of antenatal services during work hours which makes it inconvenient for male partner participation [12, 13, 16, 17, 19-26].

Male partner approval is highly correlated with a woman's use of HIV testing services [27-29]. Recent research in SSA has documented several effective interventions to promote male partner involvement, including such interventions as direct invitation to attend antenatal care-based HIV testing with their pregnant partners, offering HIV testing in bars, sending notification to partners of newly diagnosed HIV-positive women, mobile testing, and home-based testing [7, 9, 16, 20, 30-35]. The most successful interventions are those that use a combination of approaches that shift the burden of engaging the male partner from the woman to the community [36].

Nigeria has the highest burden of HIV infection in SSA. At the time of study implementation in 2013, Nigeria alone accounted for $17 \%$ of the estimated 1.3 million new HIV infections that occurred in SSA, including $26 \%$ of all new childhood infections that occurred among the 22 Global Plan priority countries [37]. Although 70\% of men in Nigeria knew where to get an HIV test, only $10 \%$ had been tested for HIV and received the results in the past 12 months, and this rate was consistently lower in hard-toreach rural communities compared to urban areas [38].

Nigeria has extensive networks of faith-based institutions, and faith plays a significant role in the social life of Nigerians [39]. In Southeastern Nigeria, the population is predominantly Christian (Catholic and Anglican) with church attendance nearing 90\% [39]. Building on this foundation, we developed the Healthy Beginning Initiative (HBI), a culturally adapted, family-centered approach that relies on the widely distributed church-based networks to promote individual testing, tracking and linkage to care [40]. HBI was designed to remove many of the barriers to male partner testing and participation in antenatal care. The intervention provides male partners with (1) community encouragement to participate in antenatal care, (2) education about the antenatal risk of HIV, (3) integrated testing to reduce stigma, (4) testing at convenient locations and (5) free testing to reduce the economic burden of testing. HBI has been found to be effective for HIV testing and linkage to care for pregnant women and exposed infants [41, 42]. This paper reports the results of HBI on HIV testing among male partners of pregnant women during pregnancy, prior to delivery. We hypothesized that male partners of pregnant women randomized to the intervention group (IG) of HBI would have a higher rate of HIV testing compared to those randomized to the standard of care control group (CG).

\section{Methods}

\section{Study Design, Church Recruitment and Randomization}

A two-arm cluster randomized design was used to evaluate the effect of HBI on the rate of HIV testing among male partners of pregnant women. A detailed research protocol, 
church selection and sample size calculations for this study has been published elsewhere [40, 41]. In summary, a total of 40 churches in 40 communities in Enugu State, Southeast Nigeria, were randomly assigned $1: 1$ to either the IG ( $N=20$ churches) or $C G(N=20$ churches). Self-identified pregnant women and their male partners 18 years and older who attended any of the study sites were eligible to participate. Participants in churches randomized to IG received health education and were offered an HIV test as part of an integrated, on-site laboratory test (hemoglobin, malaria, syphilis, HIV, sickle cell genotype, hepatitis B) during church organized baby showers prior to delivery. Participants in churches randomized to the $\mathrm{CG}$ were referred for HIV testing at their nearest healthcare facility, as is standard of care, during the church organized baby showers. The study was approved by the Institutional Review Board of the University of Nevada, Reno, and the Nigerian National Health Research Ethics Committee.

\section{Recruitment of Participants and Description of the Intervention}

Recruitment began following randomization of the churches. Each Sunday, the priest (Catholic and Anglican) asked pregnant women and their male partners in the congregation to approach the altar for a prayer. He prayed for a healthy pregnancy, successful delivery, and encouraged pregnant women to seek care at a health facility during their pregnancy. He introduced HBI, the study team, and described the program's objectives. The intervention included education about healthy pregnancy and integrated testing (hemoglobin, malaria, sickle cell genotype, HIV, hepatitis B, and syphilis), which reduced the concerns about stigma associated with HIV for participant recruitment. Pregnant women who consented could participate in the study even when the male partner was unavailable or chose not to participate. The baby showers and baby receptions were held at the churches and on Sunday to enhance participation, particularly of the male partners who worked during the week.

\section{Baby Shower (Before Infant Birth)}

A baby shower was conducted one Sunday each month for pregnant women and their families and was similar for the $\mathrm{CG}$ and the IG with the exception of the intervention. Both groups received refreshments and participated in a gift exchange. During the baby shower, pregnant women and their male partners in the CG were referred to a local health facility for antenatal care and free HIV testing. The research team maintained direct contact with health facilities to confirm HIV testing and PMTCT completion.
The intervention received by the IG included an educational game show (The Game of Love) which provided information about healthy pregnancy habits in addition to HIV acquisition modes, and effective PMTCT interventions. Participants discussed healthy habits and important laboratory tests during pregnancy. Additionally, during The Game of Love, the male partner was asked to show a sign of love to his partner. The acts that the male partners chose to perform included feeding, carrying, kissing, and dancing. During the educational program, there was a connection made between performing an act of love and participating in integrated testing with their partner. Free integrated laboratory tests (hemoglobin, malaria, sickle cell genotype, HIV, hepatitis B, and syphilis) were offered to pregnant women and their male partners during the baby shower. During the development of the intervention, male partners were asked which tests should be integrated into the test offered along with HIV. Male partners wanted hemoglobin test included because they felt having a high hemoglobin level was a sign of strength. We included this test to increase motivation for male testing and participation. Additionally, the integrated testing was designed to reduce stigma associated with HIV-only testing. Women and their male partners identified as HIV-infected were linked to Prevention, Education, Treatment, Training and Research-Global Solutions (PeTR-GS), a President's Emergency Plan for AIDS Relief (PEPFAR) supported, comprehensive program for HIV care. All counseling and follow-up HIV care took place at PeTR-GS facilities.

\section{Baby Reception (After Infant Birth)}

One Sunday every two to three months, a baby reception was held for new births in the Church. The baby reception was attended by participants in both the CG and IG. Baby gifts and refreshments were provided, and participants completed a post-delivery questionnaire that offered an opportunity to ascertain and document HIV testing during pregnancy and pregnancy outcomes in addition to gather data used in the analysis. It also provided an opportunity for follow-up with women and their male partners who needed ongoing care post-delivery. Women and their male partners in the control group were offered free integrated HIV testing at the baby reception post-delivery.

\section{Assessment and Outcome Measures}

The outcome measure was verified completed HIV testing for male partners of the pregnant women during pregnancy. Follow-up was conducted during the baby reception where post-delivery questionnaires were administered by the HT. The questionnaires were used to ascertain HIV testing during pregnancy in addition to gather data to identify 


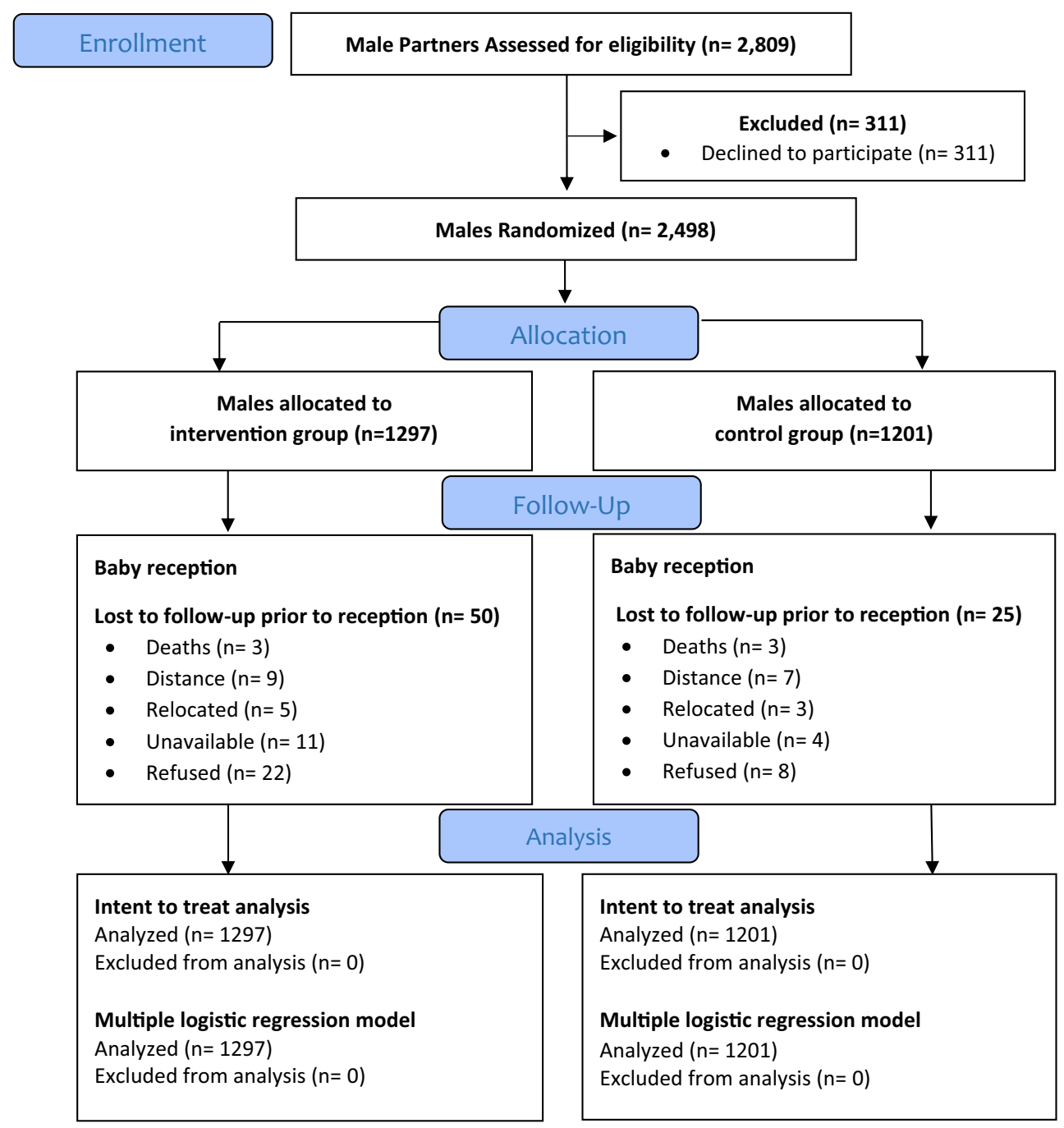

Fig. 1 Healthy beginning initiative participant flow chart

predictors of HIV testing. Male-partners were asked to selfreport HIV testing. Self-reported HIV tests were confirmed through the integrated laboratory at churches randomized to IG. Self-reported HIV tests in churches randomized to CG were confirmed at the health facility where the HIV tests reportedly took place. Only verified tests were used for analyses, and if we could not verify a test, it was considered as HIV-non-tested.

\section{Statistical Analysis}

There were two important sample estimates for the study. First is $\mathrm{N}$, the number of pregnant women and $\mathrm{K}$, the number of churches, with the pregnant women nested within the $\mathrm{K}$ churches. A detailed sample size calculation and analysis plan has been described previously [40]. Our hypothesis test was for differences in two binomial proportions at follow-up. We applied the concept of Intention-
to-Treat Analysis (ITT) for data analyses where we included all randomized subjects in the groups to which they were randomly assigned regardless of subsequent withdrawal from the program or deviation from the protocol. We included all subjects for part of the analysis and participants' previous HIV test was treated as ITT stratagem of "last-observation-carried-forward" in order to reduce the effect of withdrawal. The $\chi^{2}$ statistic was used to assess differences in HIV-Test proportions. The Student's $t$ test was used to assess differences in continuous data. Multiple logistic regression was also used to analyze the binomial variable of HIV-tested and HIV-non-tested. Multiple logistic regression allowed for the incorporation of covariates and confounders at the individual level (age, education level, and previous HIV testing). Adjusted odds ratios (aORs) between HIV-tested and HIV-non-tested men were obtained by controlling the previously mentioned covariates and potential confounding factors. All above 
Table 1 Characteristics of participants

\begin{tabular}{|c|c|c|c|c|c|c|c|c|}
\hline Characteristic & Total & & Control group & $\%$ & Intervention group & $\%$ & $\chi^{2}$ & $\mathrm{p}^{*}$ \\
\hline Total subjects & & 2498 & 1201 & & 1297 & & & \\
\hline Age & Mean (STD) & $38.32(8.12)$ & $38.48(7.83)$ & & $38.17(8.39)$ & & & .340 \\
\hline \multicolumn{9}{|l|}{ Age group } \\
\hline $16-24.9$ & & 64 & 30 & 2.51 & 34 & 2.64 & 2.49 & .288 \\
\hline $25-34.9$ & & 879 & 405 & 33.92 & 474 & 36.86 & & \\
\hline $35+$ & & 1537 & 759 & 63.57 & 778 & 60.5 & & \\
\hline \multicolumn{9}{|l|}{ Education level } \\
\hline None/primary & & 1044 & 490 & 40.90 & 554 & 43.18 & 11.82 & $.003 *$ \\
\hline Secondary & & 1102 & 517 & 43.16 & 585 & 45.60 & & \\
\hline Tertiary & & 335 & 191 & 15.94 & 144 & 11.22 & & \\
\hline \multicolumn{9}{|l|}{ Employment } \\
\hline Full time & & 1503 & 759 & 63.51 & 744 & 58.49 & 6.53 & $.038 *$ \\
\hline Part time & & 611 & 276 & 23.1 & 335 & 26.34 & & \\
\hline Unemployed & & 353 & 160 & 13.39 & 193 & 15.17 & & \\
\hline \multicolumn{9}{|l|}{ Family size } \\
\hline$\leq 2$ & & 373 & 177 & 14.77 & 196 & 15.15 & .01 & .959 \\
\hline $3-6$ & & 1785 & 859 & 71.7 & 926 & 71.56 & & \\
\hline$\geq 7$ & & 334 & 162 & 13.52 & 172 & 13.29 & & \\
\hline \multicolumn{9}{|c|}{ Distance to health facility } \\
\hline $0-5 \mathrm{~km}$ & & 879 & 434 & 36.20 & 445 & 34.36 & 4.37 & .225 \\
\hline $5-10 \mathrm{~km}$ & & 929 & 458 & 38.2 & 471 & 36.37 & & \\
\hline $10-15 \mathrm{~km}$ & & 432 & 196 & 16.35 & 236 & 18.22 & & \\
\hline $15+\mathrm{km}$ & & 254 & 111 & 9.26 & 143 & 11.04 & & \\
\hline \multicolumn{9}{|l|}{ Residency area } \\
\hline Rural & & 1691 & 745 & 62.14 & 946 & 73.62 & 37.64 & $<.001 *$ \\
\hline Urban & & 793 & 454 & 37.86 & 339 & 26.38 & & \\
\hline \multicolumn{9}{|c|}{ Self-reported previous HIV testing } \\
\hline No & & 952 & 410 & 34.13 & 575 & 44.19 & 27.14 & $<.001 *$ \\
\hline Yes & & 1470 & 791 & 65.87 & 722 & 55.81 & & \\
\hline
\end{tabular}

* Results were considered statistically significant when $\mathrm{p}<.05$

statistical significance tests were set as $\mathrm{p}$-value $<.05$ and tests were 2-sided. Statistical Analysis Systems (SAS-9.4) was used for the analyses.

\section{Results}

Enrollment began in January, 2013 and was completed in September, 2013. Follow-up of enrolled participants ended in August, 2014. Of the 3047 women enrolled in HBI, 2809 were married or partnered from which 2498 males were enrolled and participated across 40 churches, a participation rate of $88.9 \%$. Throughout the study a total of 75 participants were lost to follow-up (IG $\mathrm{n}=50$, CG $\mathrm{n}=25)$ and did not complete the post-delivery follow-up questionnaire (See Fig. 1).

\section{Demographic Characteristics}

Table 1 shows the demographic characteristics of the male partners who participated in the study. In general, participants in both control and intervention groups had similar demographic characteristics, including age, family size, and distance to the nearest health facility. However, some characteristics were significantly different. For example, participants in the control group were more likely to have tertiary level education $\left(\chi^{2}=11.82\right.$, $\mathrm{p}=.003$ ), more likely to have full time employment $\left(\chi^{2}=6.5, p=.038\right)$, more likely to reside in urban areas $\left(\chi^{2}=37.64, \mathrm{p}<.001\right)$, and more likely to have previously tested for HIV $\left(\chi^{2}=27.14, p<.001\right)$. We controlled for significant differences in subsequent analyses. 
Table 2 Confirmed HIV tests and predictors of HIV testing among males

\begin{tabular}{|c|c|c|c|c|c|c|}
\hline & & ts $(\mathrm{N})$ & Tested $(\mathrm{N})$ & Rate $(\%)$ & $\chi^{2}$ & $\mathrm{p}^{*}$ \\
\hline \multirow[t]{2}{*}{ Confirmed HIV test } & Control & 1201 & 453 & 37.71 & 564.48 & $<.001 *$ \\
\hline & Intervention & 1297 & 1089 & 84.00 & & \\
\hline \multirow[t]{3}{*}{ Age group } & $16-24.9$ & 63 & 35 & 55.56 & 2.55 & .279 \\
\hline & $25-34.9$ & 852 & 551 & 64.67 & & \\
\hline & $35+$ & 1514 & 949 & 62.68 & & \\
\hline \multirow[t]{3}{*}{ Education level } & None/Primary & 1026 & 632 & 61.60 & 3.18 & .204 \\
\hline & Secondary & 1080 & 681 & 63.06 & & \\
\hline & Tertiary & 325 & 218 & 67.08 & & \\
\hline \multirow[t]{3}{*}{ Employment } & Full time & 1477 & 931 & 63.03 & .34 & .843 \\
\hline & Part time & 593 & 376 & 63.41 & & \\
\hline & Unemployed & 346 & 213 & 61.56 & & \\
\hline \multirow[t]{3}{*}{ Family Size } & $\leq 2$ & 366 & 238 & 65.03 & .77 & .679 \\
\hline & $3-6$ & 1746 & 1095 & 62.71 & & \\
\hline & $\geq 7$ & 329 & 205 & 62.31 & & \\
\hline \multirow[t]{4}{*}{ Distance to Health Facility } & $0-5 \mathrm{~km}$ & 862 & 523 & 60.67 & 5.07 & .167 \\
\hline & $5-10 \mathrm{~km}$ & 908 & 572 & 63.00 & & \\
\hline & $10-15 \mathrm{~km}$ & 425 & 278 & 65.41 & & \\
\hline & $15+\mathrm{km}$ & 248 & 167 & 67.34 & & \\
\hline \multirow[t]{2}{*}{ Residency area } & Rural & 1652 & 1048 & 63.44 & .58 & .447 \\
\hline & Urban & 781 & 483 & 61.84 & & \\
\hline \multirow[t]{2}{*}{ Ever tested for HIV (self-Reported) } & No & 985 & 582 & 59.09 & 4.31 & $.038 *$ \\
\hline & Yes & 1513 & 960 & 63.45 & & \\
\hline
\end{tabular}

* Results were considered statistically significant when $\mathrm{p}<.05$

\section{HIV Testing Among Male Partners}

Table 2 shows differences in rates of HIV testing and other related factors between control and intervention groups. Verified HIV testing rate among male partners were significantly higher in IG (84.00\%) compared to CG (37.71\%) $\left(\chi^{2}=564.48, \mathrm{p}<.001\right)$. Only self-reported previous HIV testing was significantly associated with higher HIV testing rates, indicating that men who previously had HIV testing were more likely to engage in HIV testing during this intervention (63.45 vs. $59.09 \%, \mathrm{p}=.038)$.

\section{Adjusted Odds Ratio for Not Getting HIV Test Among Male Partners}

Table 3 shows the adjusted odds ratios after controlling for demographic factors and other potential predictors for not having an HIV test among male partners of pregnant women. Male partners in intervention group were 12 times more likely to have a confirmed HIV test compared to male partners in control group after controlling for age, education, employment, area of residence, household size and a history of previous HIV testing (AOR: 11.67, 95\% CI
9.4-14.4; $\mathrm{p}<.001)$. Having a tertiary school education and self-reported previous HIV testing were significantly associated with having an HIV test.

\section{Discussion}

Findings from this study demonstrated that the intervention (i.e., culturally appropriate, congregation-based provision of education and onsite HIV testing to male partners of pregnant women during church organized baby showers for pregnant women) was more effective than standard care (i.e., referral to health facility to obtain education and HIV test), even though the male partners in the control group were exposed to part of the intervention which included a baby shower and reception. Male partners of pregnant women enrolled in the intervention group were 12 times more likely to have tested for HIV compared to male partners of pregnant women in the control group.

Exclusion of male partners during PMTCT programs reinforces the cultural notion that antenatal care and HIV/ AIDS prevention are primarily a problem for women, and that responsibility for preventing transmission of HIV to 
Table 3 Multiple logistic regression and adjusted odds ratios for determinants of HIV test among male partners

\begin{tabular}{|c|c|c|c|}
\hline Variable & AOR & $95 \% \mathrm{CI}$ & $\mathrm{p}$ value \\
\hline \multicolumn{4}{|l|}{ Confirmed HIV test } \\
\hline Intervention group & 11.96 & $9.63-14.79$ & $<.001^{*}$ \\
\hline \multicolumn{4}{|l|}{ Age group } \\
\hline $35+$ compared to $16-24.9$ & 1.21 & $.77-2.67$ & 642 \\
\hline $35+$ compared $25-34.9$ & .98 & $.80-1.23$ & 608 \\
\hline \multicolumn{4}{|l|}{ Education level } \\
\hline Tertiary compared to none/primary & 1.53 & $1.12-2.08$ & $.046^{*}$ \\
\hline Tertiary compared to secondary & 1.53 & $1.11-2.12$ & .068 \\
\hline \multicolumn{4}{|l|}{ Working } \\
\hline Full-time compared to part-time & 1.03 & $.81-1.31$ & .830 \\
\hline Full-time compared to unemployed & 1.12 & $.84-1.50$ & .490 \\
\hline \multicolumn{4}{|l|}{ Distance to healthcare facility } \\
\hline $0-5 \mathrm{KM}$ compared to $5-10 \mathrm{KM}$ & 1.01 & $.75-1.37$ & .846 \\
\hline $0-5 \mathrm{KM}$ compared to $10-15 \mathrm{KM}$ & .98 & $.79-1.23$ & .504 \\
\hline $0-5 \mathrm{KM}$ compared to $15+\mathrm{KM}$ & 1.16 & $.81-1.65$ & .390 \\
\hline \multicolumn{4}{|l|}{ Household size } \\
\hline$\geq 7$ compared to $\leq 2$ & 1.16 & $.87-1.55$ & .515 \\
\hline$\geq 7$ compared to $3-6$ versus & 1.16 & $.80-1.70$ & 617 \\
\hline \multicolumn{4}{|l|}{ Living area } \\
\hline Rural compared to urban & .90 & $.72-1.21$ & .356 \\
\hline \multicolumn{4}{|l|}{ Self-reported previous HIV testing } \\
\hline Yes compared to no & 1.61 & $1.30-2.00$ & $<.001 *$ \\
\hline
\end{tabular}

* Results were considered statistically significant when $\mathrm{p}<.05$

their unborn babies is women's sole responsibility. Nigeria is one of the 22 Global Plan priority countries that account for $90 \%$ of pregnant women living with HIV [37, 38, 43]. Despite improved efforts dedicated to the PMTCT, less than $20 \%$ of pregnant women in Nigeria were tested for HIV in 2013, only $27 \%$ of HIV-infected pregnant women received antiretroviral (ARV) therapy; and only $12 \%$ of HIV exposed infants received ARV prophylaxis for PMTCT [43-45]. The low rates of testing and treatment in Nigeria contributed to an estimated 58,000 HIV-infected infants in 2014 [44]. Finding new approaches to promote male partner involvement are necessary to realize the WHO/PEPFAR goal of eliminating new pediatric HIV infections [5].

Findings from this study support the existing body of evidence which shows that community-based programs to increase uptake of HTC are effective [6, 7, 16, 35, 36, 46]. Our intervention saw a male participation rate $(88.9 \%)$ which outpaced other interventions to increase male participation in antenatal care in SSA that range between 16 and $35 \%[7,16,34]$. Additionally, the rate of HIV testing among males was higher in both our IG $(86.4 \%)$ and CG (38.2\%) compared to the overall rate of HIV testing among males in Nigeria (23\%) [47]. We believe the effectiveness of this intervention resulted mostly from its ability to address several individual, community, and health systems barriers that limit the involvement of male partners in antenatal care $[6,12,14,17,47]$. In cultures where programs associated with pregnancy and childbirth are traditionally regarded as women-only programs, male partners are unlikely to attend. To overcome this barrier, we involved male partners during the development of the intervention. Their suggestions during program development were critical to the success of the intervention. In a marked departure from most current practices, we implemented an approach that: (a) integrated HTC into an existing community-based, culturally-adapted and socially accepted institution; (b) chose to implement the intervention close to where the male partners live and congregate; (c) chose an integrated approach to education and testing that reduced the stigma associated with HIV-only testing; and (d) involved the male partners in specific activities. By implementing the program close to where male partners live, we reduced the barrier for them of having to take additional time away from work to attend antenatal care with their partners. Additionally, we gave male partners the role of presenting the baby shower gift to their pregnant partners during the baby shower. This provided a mechanism for the male partners to become actively involved in antenatal care outside of the health facility. The cultural environment in Nigeria is similar to other priority subSaharan Africa (SSA) countries which considers pregnancy to be a "women's affair" and discourages "encroachment" by men $[12,14]$. However, studies have shown that the majority of women want their male partners to participate in their pregnancy [8].

While interpreting the results of this study and contemplating its adaptation in other settings, it is important to consider the contextual factors that contributed to its success. For example, this program was successful because of the active and enthusiastic support of religious leaders and because it was conducted within an environment where religious institutions and their leaders have a strong influence in the community. For adaptation in other settings, influential leaders need to be identified and their support needs to be enlisted. Additionally, HBI was successful because HIV prevention fell within the cultural and spiritual values of religious leaders in Southeastern Nigeria. For example, many churches in Nigeria provide HIV counseling as part of pre-marital counseling of couples; some require mandatory proof of HIV testing as a condition for marriage [48]. For adaption of HBI in other geographic locations (i.e. mosques in northern Nigeria or Hindu temples in India), it must first be established that HIV prevention fits within the cultural and spiritual values of the influential leaders [49]. In Southeastern Nigeria, we identified churches as a place where people 'congregate'. The place of 'congregation' will 
vary in other settings and this intervention might be adaptable to these settings. Additionally, HBI may be scaled up to include additional health screenings for other diseases such as diabetes and hypertension or mental health disorders, allowing HBI to serve as a valuable health resource in resource limited communities.

\section{Limitations}

We conducted this study in Southeastern Nigeria where there is a high Christian church attendance rate. The generalizability of our findings to predominantly Muslim states in Nigeria, or other countries with lower church attendance rates may be limited. We only used verified HIV test. If test could not be verified (i.e. test was conducted at a health fair not associated with a health facility) it was counted as a non-test. This may have resulted in under counting of HIV tests. The questionnaire was written at a sixth grade reading level. We encountered a large number of participants who could not read English or the local language. We relied on the HT to administer the questionnaire because of the low rates of literacy. Other than verification of HIV testing, the rest of the data collected on the questionnaire were self-report. Face-to-face administration of the questionnaire and self-report may have introduced bias.

\section{Conclusion}

This culturally adapted, family-centered, congregationbased intervention was effective in increasing HIV testing among male partners of pregnant women in Southeastern Nigeria. HBI or similar culturally appropriate platforms can be utilized to implement other health interventions designed for both communicable and non-communicable diseases in low-income countries with similar enabling contextual factors.

Acknowledgements We are grateful to HealthySunrise Foundation, Bishop John Okoye (Catholic Bishop of Awgu diocese), Arch. Bishop Emmanuel Chukwuma (Anglican Bishop of Enugu), Bishop Callistus Onaga (Catholic Bishop of Enugu) and Arch. Bishop Amos Madu (Anglican Bishop of Oji-River). Their support was instrumental to the successful implementation of HBI. HBI implementation would not have been possible without the support and tireless effort of the priests in the participating churches. The church-based Volunteer Health Advisors took ownership of the program and made the process of recruitment and implementation smooth for our study team and participants. This study would have been impossible to conduct without the support of PeTR-GS (our PEPFAR-supported partner) staff and volunteers. Alexander Lyubechansky provided valuable assistance with literature review.

Funding The research was co-funded by the Eunice Kennedy Shriver National Institute of Child Health and Human Development
(NICHD), the National Institute of Mental Health (NIMH), the President's Emergency Plan for AIDS Relief (PEPFAR) under award number R01HD075050 to EE. Trial Registration: Clinicaltrials.gov identifier: NCT01795261. The funding agencies played no role in the study conception, design, data collection, data analysis, data interpretation or writing of the report.

\section{Compliance with ethical standards}

Conflict of interest Authors declare no conflicts of interest.

Ethical approval All procedures performed in studies involving human participants were in accordance with the ethical standards of the institutional and/or national research committee and with the 1964 Helsinki declaration and its later amendments or comparable ethical standards. This study was approved by the Institutional Review Board of the University of Nevada, Reno, and the Nigerian National Health Research Ethics Committee.

Informed consent Informed consent was obtained from all individual participants included in the study.

Open Access This article is distributed under the terms of the Creative Commons Attribution 4.0 International License (http://crea tivecommons.org/licenses/by/4.0/), which permits unrestricted use, distribution, and reproduction in any medium, provided you give appropriate credit to the original author(s) and the source, provide a link to the Creative Commons license, and indicate if changes were made.

\section{References}

1. Farquhar C, Kiarie JN, Richardson BA, Kabura MN, John FN, Nduati RW, et al. Antenatal couple counseling increases uptake of interventions to prevent HIV-1 transmission. J Acquir Immune Defic Syndr. 2004;37(5):1620-6.

2. Aluisio A, Richardson BA, Bosire R, John-Stewart G, MboriNgacha D, Farquhar C. Male antenatal attendance and HIV testing are associated with decreased infant HIV infection and increased HIV-free survival. J Acquir Immune Defic Syndr. 2011;56(1):76-82.

3. Jones D, Peltzer L, Villar-Loubet O, Shikwane E, Cook R, Peltzer $\mathrm{L}$, Vamos S, et al. Reducing the risk of HIV infection during pregnancy among South African women: A randomized controlled trial. AIDS Care. 2013;25(6):702-9.

4. Msuya SE, Mbizvo E, Hussain A, Uriyo J, Sam N, Stray-Pedersen B. Low male partner participation in antenatal HIV counselling and testing in northern Tanzania: implications for preventive programs. AIDS Care. 2008;20(6):700-9.

5. UNAID. Joint United Nations Programmes on HIV/AIDS, 2013 progress report on the global paln towards elimination of new HIV infections among children by 2015 and keeping their mothers alive. 2014. http://www.unaids.org/sites/default/files/en/ media/unaids/contentassets/documents/unaidspublication/2013/ 20130625_progress_global_plan_en.pdf.

6. Katz DA, Kiarie JN, John-Stewart GC, Richardson BA, John FN, Farquhar C. Male perspectives on incorporating men into antenatal HIV counseling and testing. PLoS ONE. 2009;4(11):e7602.

7. Byamugisha R, Astrom AN, Ndeezi G, Karamagi CA, Tylleskar $\mathrm{T}$, Tumwine JK. Male partner antenatal attendance and HIV testing in eastern Uganda: a randomized facility-based intervention trial. J Int AIDS Soc. 2011;14:1.

8. Nkuoh GN, Meyer DJ, Nshom EM. Women's attitudes toward their partners' involvement in antenatal care and prevention of 
mother-to-child transmission of HIV in Cameroon, Africa. J Midwifery Women's Health. 2013;58(1):83-91.

9. Haile F, Brhan Y. Male partner involvements in PMTCT: A cross sectional study, Mekelle, Northern Ethiopia. BMC Pregnancy and Childbirth. 2014;14(1):1.

10. Kalembo FW, Zgambo M, Mulaga AN, Yukai D, Ahmed NI. Association between male partner involvement and the uptake of prevention of mother-to-child transmission of HIV (PMTCT) interventions in Mwanza district, Malawi: a retrospective cohort study. PLoS ONE. 2013;8(6):e66517.

11. Sherr L, Croome N. Involving fathers in prevention of mother to child transmission initiatives - what the evidence suggests. J Int AIDS Soc. 2012;15(4).

12. Falnes EF, Moland KM, Tylleskär T, de Paoli MM, Msuya SE, Engebretsen IM. It is her responsibility": partner involvement in prevention of mother to child transmission of HIV programmes, northern Tanzania. J Int AIDS Soc. 2011;14(1):21.

13. Auvinen J, Kylmä J, Välimäki M, Bweupe M, Suominen T. Barriers and resources to PMTCT of HIV: luba-Kasai men's perspective in Lusaka, Zambia. J Assoc Nurses AIDS Care. 2013;24(6):554-68.

14. Morfaw F, Mbuagbaw L, Thabane L, Rodrigues C, Wunderlich A, Nana P, et al. Male involvement in prevention programs of mother to child transmission of HIV: a systematic review to identify barriers and facilitators. Syst Rev. 2013;2(1):1.

15. Auvinen J, Kylma J, Suominen T. Male involvement and prevention of mother-to-child transmission of HIV in Sub-Saharan Africa: an integrative review. Curr HIV Res. 2013;11(2):169-77.

16. Ditekemena J, Matendo R, Koole O, Colebunders R, Kashamuka M, Tshefu A, et al. Male partner voluntary counselling and testing associated with the antenatal services in Kinshasa, Democratic Republic of Congo: a randomized controlled trial. Int J STD AIDS. 2011;22(3):165-70.

17. Nkuoh GN, Meyer DJ, Tih PM, Nkfusai J. Barriers to men's participation in antenatal and prevention of mother-to-child HIV transmission care in Cameroon, Africa. J Midwifery Women's Health. 2010;55(4):363-9.

18. Theuring S, Mbezi P, Luvanda H, Jordan-Harder B, Kunz A, Harms G. Male involvement in PMTCT services in Mbeya Region, Tanzania. AIDS and Behav. 2009;13(1):92-102.

19. Reece M, Hollub A, Nangami M, Lane K. Assessing male spousal engagement with prevention of mother-to-child transmission (pMTCT) programs in western Kenya. AIDS Care. 2010;22(6):743-50.

20. Brusamento S, Ghanotakis E, Tudor Car L, van-Velthoven MH, Majeed A, Car J. Male involvement for increasing the effectiveness of prevention of mother-to-child HIV transmission (PMTCT) programmes. Cochrane Database Syst Rev. 2012; 17:10.

21. Larsson EC, Thorson A, Nsabagasani X, Namusoko S, Popenoe R, Ekstrom AM. Mistrust in marriage-reasons why men do not accept couple HIV testing during antenatal care- a qualitative study in eastern Uganda. BMC Public Health. 2010;10(1): 1

22. Koo K, Makin JD, Forsyth BW. Barriers to male-partner participation in programs to prevent mother-to-child HIV transmission in South Africa. AIDS Educ Prev. 2013;25(1):14.

23. Turan JM, Bukusi EA, Onono M, Holzemer WL, Miller S, Cohen CR. HIV/AIDS stigma and refusal of HIV testing among pregnant women in rural Kenya: results from the MAMAS Study. AIDS Behav. 2011;15(6):1111-20.

24. Grede N, de Pee S, Bloem M. Economic and social factors are some of the most common barriers preventing women from accessing maternal and newborn child health $(\mathrm{MNCH})$ and prevention of mother-to-child transmission (PMTCT) services: a literature review. AIDS Behav. 2014;18(5):516-30.
25. Akarro RR, Deonisia M, Sichona F. An evaluation of male involvement on the programme for PMTCT of HIV/AIDS: a case study of Ilala Municipality in Dar es Salaam Tanzania. Arts Soc Sci J. 2011;20:1.

26. Taylor NK, Buttenheim AM. Improving utilization of and retention in PMTCT services: can behavioral economics help? BMC Health Serv Res. 2013;13(1):1.

27. Maman S, Mbwambo J, Hogan N, Kilonzo G, Sweat M. Women's barriers to HIV-1 testing and disclosure: challenges for HIV-1 voluntary counselling and testing. AIDS Care. 2001;13(5):595-603.

28. Baiden F, Remes P, Baiden R, Williams J, Hodgson A, Boelaert $\mathrm{M}$, et al. Voluntary counseling and HIV testing for pregnant women in the Kassena-Nankana district of northern Ghana: is couple counseling the way forward? AIDS Care. 2005; 17(5):648-57.

29. Homsy J, Kalamya JN, Obonyo J, Ojwang J, Mugumya R, Opio $\mathrm{C}$, et al. Routine intrapartum HIV counseling and testing for prevention of mother-to-child transmission of HIV in a rural Ugandan hospital. J Acquir Immune Defic Syndr. 2006;42(2):149-54.

30. Betancourt TS, Abrams EJ, McBain R, Fawzi MCS. Familycentred approaches to the prevention of mother to child transmission of HIV. Journal of the International AIDS Society. 2010;13(2): 1 .

31. Auvinen J, Suominen T, Välimäki M. Male participation and prevention of human immunodeficiency virus (HIV) mother-tochild transmission in Africa. Psychol Health Med. 2010;15(3):288-313.

32. Becker S, Mlay R, Schwandt HM, Lyamuya E. Comparing couples' and individual voluntary counseling and testing for HIV at antenatal clinics in Tanzania: a randomized trial. AIDS Behav. 2010;14(3):558-66.

33. Peltzer K, Jones D, Weiss SM, Shikwane E. Promoting male involvement to improve PMTCT uptake and reduce antenatal HIV infection: a cluster randomized controlled trial protocol. BMC Public Health. 2011;11(1):778.

34. Mohlala BK, Boily MC, Gregson S. The forgotten half of the equation: randomized controlled trial of a male invitation to attend couple voluntary counselling and testing. AIDS. 2011;25(12):1535-41.

35. Hensen B, Lewis J, Schaap A, Tembo M, Mutale W, Weiss H, et al. Factors associated with HIV-testing and acceptance of an offer of home-based testing by men in Rural Zambia. AIDS Behav. 2014;19(3):492-504.

36. Dunlap J, Foderingham N, Bussell S, Wester CW, Audet CM, Aliyu MH. Male involvement for the prevention of mother-tochild HIV transmission: a brief review of initiatives in East, West, and Central Africa. Current HIV/AIDS Rep. 2014;11(2):109-18.

37. UNAID. Joint United Nations Programmes on HIV/AIDS. The gap report. 2014.

38. National Agency for the Control of AIDS (NACA). Federal Republic of Nigeria: global AIDS response country progress report. 2014. http://www.unaids.org/sites/default/files/country/ documents/NGA_narrative_report_2014.pdf.

39. Pew Research Center. Tolerance and tension: islam and christianity in sub-saharan Africa. 2010. http://www.pewforum.org/ files/2010/04/sub-saharan-africa-full-report.pdf.

40. Ezeanolue EE, Obiefune MC, Yang W, Obaro SK, Ezeanolue $\mathrm{CO}$, Ogedegbe GG. Comparative effectiveness of congregationversus clinic-based approach to prevention of mother-to-child HIV transmission: study protocol for a cluster randomized controlled trial. Implement Sci. 2013;8(1):1.

41. Ezeanolue E, Obiefune M, Ezeanolue C, Ehiri J, Osuji A, Ogidi $\mathrm{A}$, et al. Impact of a Congregation-based intervention on uptake 
of HIV testing among pregnant women in Nigeria: the Baby Shower cluster randomized trial. Lancet Glob Health. 2015;3: e692-700.

42. Pharr JR, Obiefune MC, Ezeanolue CO, Osuji A, Ogidi AG, Gbadamosi S, et al. Linkage to care, early infant diagnosis, and perinatal transmission Among infants Born to HIV-infected nigerian mothers: evidence from the healthy beginning initiative. J Acquir Immune Defic Syndr. 2016;1(72 Suppl 2):S154-60.

43. National Agency for the Control of AIDS (NACA). Global AIDS Response Country Progress Report: Nigeria GARPR 2015. 2015. http://www.unaids.org/sites/default/files/country/documents/NGA_ narrative_report_2014.pdf.

44. (44) UNAIDS. 2015 Progress report on the global plan. 2015. http://www.unaids.org/sites/default/files/media_asset/JC2774_ 2015ProgressReport_GlobalPlan_en.pdf.

45. UNAID. Joint United Nations Programmes on HIV/AIDS, Global report: UNAIDS report on the Global AIDS epidemic 2013. 2014. http://www.unaids.org/sites/default/files/en/media/unaids/
contentassets/documents/epidemiology/2013/gr2013/UNAIDS_ Global_Report_2013_en.pdf.

46. Coates TJ, Kulich M, Celentano DD, Zelaya CE, Chariyalertsak $\mathrm{S}$, Chingono A, et al. Effect of community-based voluntary counselling and testing on HIV incidence and social and behavioural outcomes (NIMH Project Accept; HPTN 043): a clusterrandomised trial. Lancet Glob Health. 2014;2(5):e267-77.

47. Osoti AO, John-Stewart G, Kiarie J, Richardson B, Kinuthia J, Krakowiak D, et al. Home visits during pregnancy enhance male partner HIV counselling and testing in Kenya: a randomized clinical trial. AIDS. 2014;28(1):95-103.

48. Uneke C, Alo M, Ogbu O. Mandatory pre-marital HIV testing in Nigeria: the public health and social implications. AIDS Care. 2007;19(1):116-21.

49. Campbell MK, Hudson MA, Resnicow K, Blakeney N, Paxton A, Baskin M. Church-based health promotion interventions: evidence and lessons learned. Annu Rev Public Health. 2007;28:213-34. 